\title{
EVOLUÇÃO DO USO DE CARVÕES “SOFT” E “STEAM COAL" NA COQUEIRA HR - TECNOLOGIA SUNCOKE ENERGY - E IMPACTOS NA QUALIDADE DO COQUE E NO CUSTO DAS MISTURAS*
}

Amilton Ferreira de Oliveira ${ }^{1}$ José Eustáquio da Silvar ${ }^{2}$

\section{Resumo}

Este trabalho se propõe a mostrar os resultados obtidos pela SunCoke Energy Brasil após as mudanças do perfil da mistura de carvões, na qual foram acrescidas criteriosamente as participações dos carvões denominados "soft" e carvões "steam coal", seguido da redução também criteriosa dos carvões médio voláteis. A consolidação dos dados de qualidade do coque e do custo das misturas comprova que as modificações no perfil das misturas foram bem sucedidas, pois a qualidade do coque se manteve conforme a expectativa dos clientes (Altos-Fornos) e o custo das misturas apresentou uma significativa redução. Todos os testes e experimentos adotados foram embasados na utilização na metodologia denominada "Método e aparelho para avaliar as propriedades de coqueificação do carvão", também conhecida como Box Test, e ainda no profundo estudo das características dos carvões utilizados e os impactos destes na qualidade do coque.

Palavras-chave: Mudança de perfil de mistura; Qualidade de coque; Redução de custo; Flexibilidade operacional.

\section{THE EVOLUTION THE USE OF "SOFT" AND "STEAM" COALS AT SUNCOKE ENERGY AND THE IMPACTS ON COKE QUALITY AND IN THE COST OF THE COAL BLENDS}

\begin{abstract}
This paper aims to show the results obtained by SunCoke Energy Brazil after the changes in the profile of coal blends, which were carefully designed in order the increase the amount of "soft coals" and "steam coals" on the coal blends, followed by the decreasing of the medium volatile coals. The data consolidation of the coke quality and the relative average cost of the coal blends shows that the changes in the profile of the coal blends were successful once the coke quality remained as expected by the customers (Blast Furnace) and the relative average cost of the coal blends showed a significant reduction. All the tests and experiments were based on the method called "Method and apparatus for evaluating the properties of coal coking", also known as Box Test and in-depth study of the coal characteristics and the impacts of them on coke quality.
\end{abstract}

Keywords: Coal blend profile; Coke Quality; Cost reduction; Operational flexibility.

1 Engenheiro de Qualidade, SunCoke Energy Brasil, cidade, estado.

2 Coordenador de Qualidade, SunCoke Energy Brasil, cidade, estado. 


\section{INTRODUÇÃO}

Por muitos anos a grande maioria dos estudos e desenvolvimento de processos de produção de coque, focavam somente nos avanços e desafios relativos às coquerias by-products. Com a crescente preocupação da humanidade com as questões ambientais, todos os seguimentos industriais, em especial a siderurgia, vêm sendo alvo de severas cobranças, sob forma de leis e decretos, para que as agressões ambientais sejam minimizadas. O processo heat recovery da SunCoke Energy configura-se como uma alternativa limpa e diferenciada para a produção de coque metalúrgico. Outro fator preponderante da tecnologia heat recovery é o fato de não haver limitações quanto ao uso de carvões com elevada pressão de coqueificação, altamente indesejáveis nas coquerias by-products, além de ser possível o uso de elevados percentuais de carvões fracamente coqueificáveis, não coqueificáveis, e os carvões denominados "steam coal" cujo uso em larga escala, são nas usinas termoelétricas. Neste trabalho é evidenciada a evolução do consumo de carvões fracamente coqueificáveis, não coqueificáveis, coque de petróleo e carvões "steam coal" na coqueria heat recovery da SunCoke Energy Brasil, passados 09 anos de operação. Além da evolução do uso dos insumos citados, são mostrados os impactos na qualidade do coque e no custo da mistura, comprovando a eficiência e a grande flexibilidade desta tecnologia.

\section{MATERIAIS E MÉTODOS}

Utilizou-se como metodologia um rigoroso controle estatístico dos dados operacionais da planta SunCoke Energy Brasil, além de diversos experimentos utilizando-se a tecnologia patenteada pela SunCoke denominada "Caracterização de Carvões para Coqueificação", também conhecida como Box Test de modo a comprovar, ou não, a viabilidade do uso de determinados carvões nos fornos da coqueria. Outro fator muito utilizado durante o decorrer dos experimentos, foi a completa caracterização dos carvões, das misturas e do coque produzido no laboratório da SunCoke, cuja modernização de suas instalações se deu em Maio de 2013, tornando-se um dos mais completos do Brasil.

\subsection{O Processo Heat Recovery da Suncoke Energy}

Após o carregamento do forno, a coqueificação inicia-se ativada pelo calor remanescente no forno em função do ciclo anterior. Os voláteis liberados da massa de carvão e seus produtos de combustão são parcialmente queimados no interior da câmara sobre a camada de carvão. O ar primário para a combustão é introduzido através de válvulas de ar situadas nas portas do forno e dispostas acima do nível de carga. Os gases parcialmente queimados deixam o interior da câmara, através de dutos descendentes (downcomers) situados nas paredes em direção ao sistema de câmara de combustão (sole flues) situado abaixo da sola do forno. O fluxo de gás é resultado da tiragem induzida mantendo assim os fornos sob pressão negativa. A combustão dos gases parcialmente queimados na câmara do forno prossegue no trajeto do gás através dos downcomers e é completada na região do sole flue.

O tempo médio do ciclo de coqueificação é de 48 horas, podendo variar de 24 a 96horas, período este em que é desenvolvida uma lenta taxa de coqueificação em temperaturas controladas. Os gases queimados deixam as câmaras de combustão por dutos ascendentes em direção a um túnel de captação comum a todos os fornos da bateria e em seguida são direcionadas para as caldeiras, nas quais há a troca de 
calor do gás com a água gerando vapor de alta pressão e alta temperatura. $\mathrm{O}$ vapor produzido é enviado para as turbinas para a geração de energia elétrica, sendo que o gás após trocar de calor com a água é direcionado para a unidade de Dessulfuração, onde é devidamente tratado, antes de ser liberado para a atmosfera. A figura 1 mostra uma configuração típica dos fornos da SunCoke.

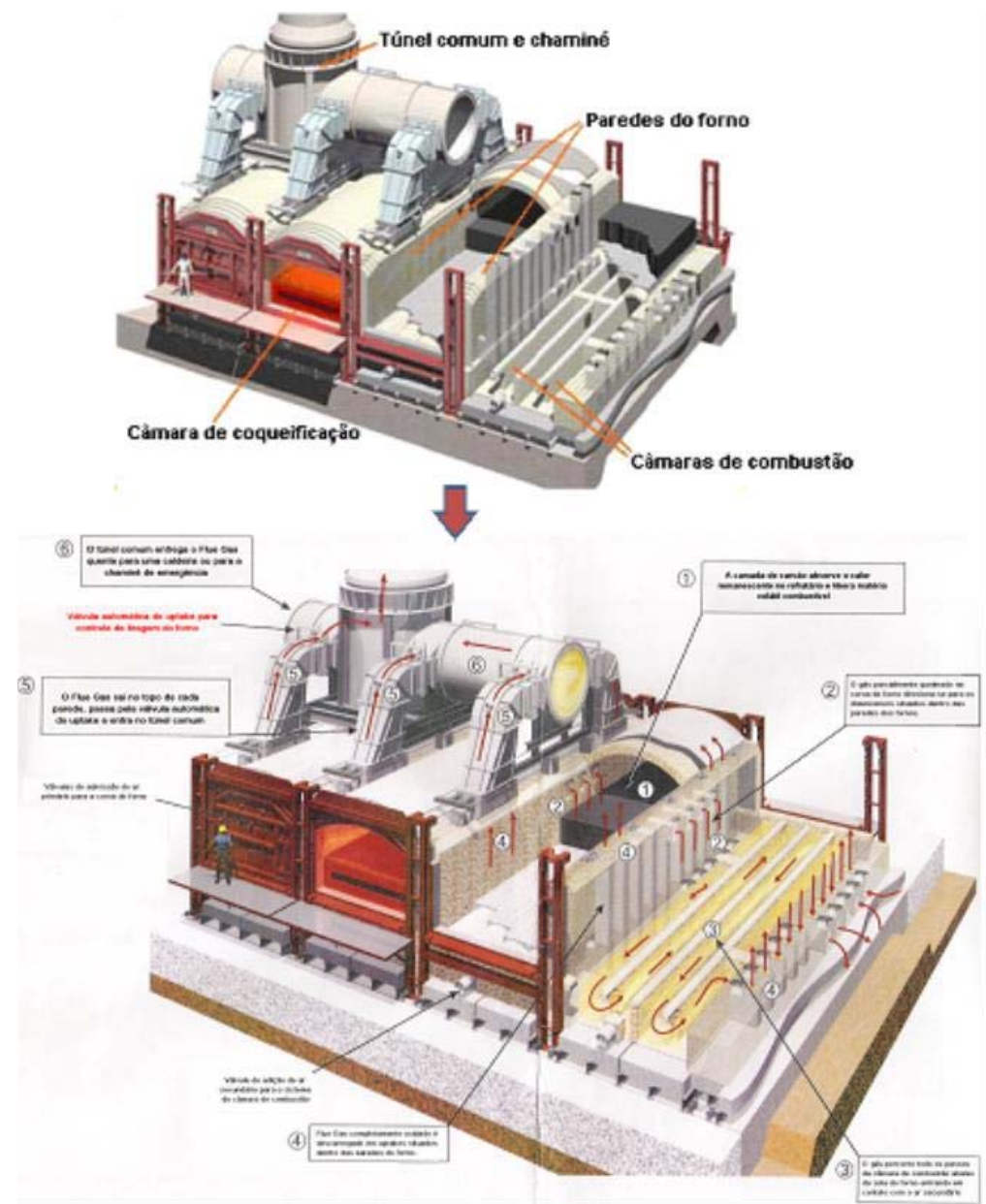

Figura 1. Configuração dos fornos da SunCoke Energy

\subsubsection{Método para caracterização de carvões "box test"}

A metodologia de utilização de box test para caracterização de carvões em coquerias heat recovery teve a patente concedida pelo INIPI à SunCoke em dezembro de 2014 sob o $n^{\circ}$ BR 102013005688-0. Trata-se de um eficiente e assertivo método para caracterização de carvões e mistura, visto que o dispositivo utilizado foi especialmente desenvolvido para simular as mesmas condições operacionais em que as misturas são submetidas, eliminando assim as inerentes limitações dos tradicionais fornos-pilotos, principalmente custo, controle térmico e tamanho da amostra. A caixa utilizada preserva algumas referências geométricas dos fornos da SunCoke Energy, tem capacidade para simular diferentes níveis de densidade da mistura, possui duplo compartimento que permite o teste simultâneo de dois materiais diferentes, como também pode ser reutilizada até quatro vezes. $O$ termo "Box Test" aqui empregado, não se caracteriza apenas com uma caixa de teste, mas sim como uma criteriosa metodologia para caracterização de carvões que engloba seguintes as fases: 1)definição de misturas; 2)elaboração de misturas em laboratório; homogeneização das misturas; 3)britagem seletiva das misturas; 4) controle de umidade e densidade da mistura; 5) controle de abastecimento da caixa; 
6) controle térmico durante a coqueificação; 7) resfriamento da caixa; 8) classificação do coque (coque de sole flue e coque de crown) e 9) caracterização completa do coque (análise imediata, análise elementar, granulometria, CRI, CSR e DI).

A figura a seguir (figura 2) mostra uma compilação de algumas fases para a realização do "Box Test".
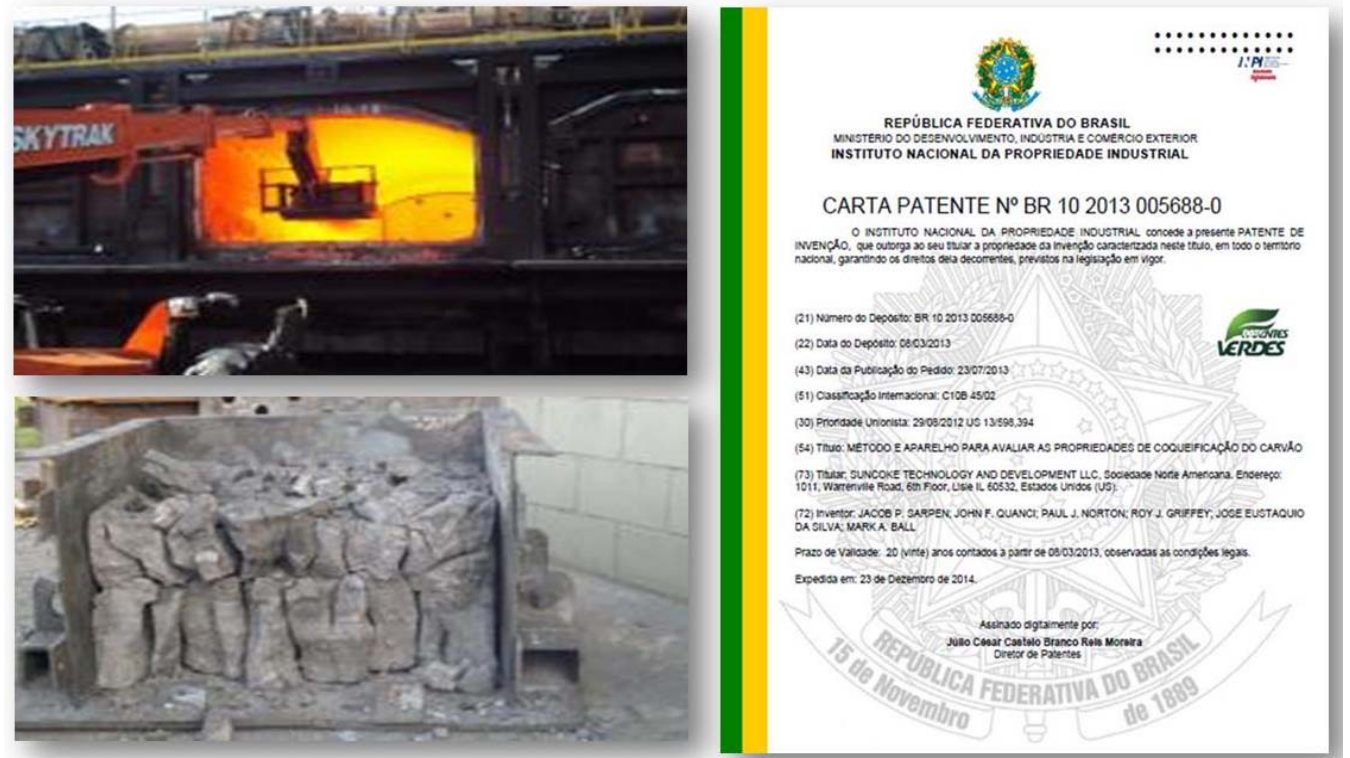

Figura 2. Box Test - SunCoke Energy.

\section{RESULTADOS E DISCUSSÃO}

Em função dos entraves logísticos que as usinas siderúrgicas brasileiras enfrentam e da total dependência da importação de carvões, a troca constante de misturas torna-se praticamente inevitável. Na figura abaixo (figura 3), observa-se a evolução de trocas de misturas (cerca de 650), realizadas na SunCoke Energy Brasil desde 2008 evidenciando-se, ao longo dos anos, a alteração do perfil das misturas cujo foco foi maximizar a qualidade e minimizar o custo.

\section{Evolução do Perfil das Misturas}

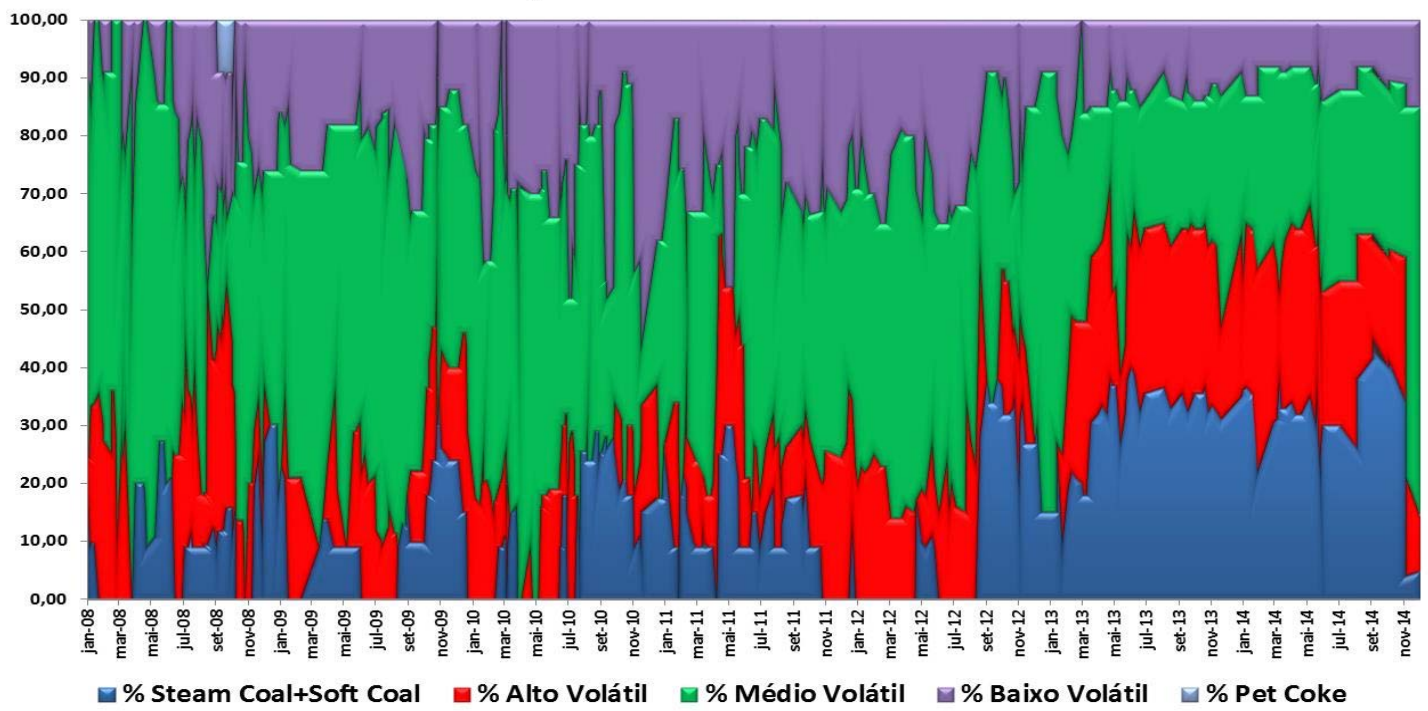

Figura 3. Evolução do Perfil das Misturas. 
Na figura 4, é mostrada a compilação de todas as misturas utilizadas, agrupadas por ano de utilização evidenciando a evolução do consumado somado dos carvões "soft" e "steam coal".

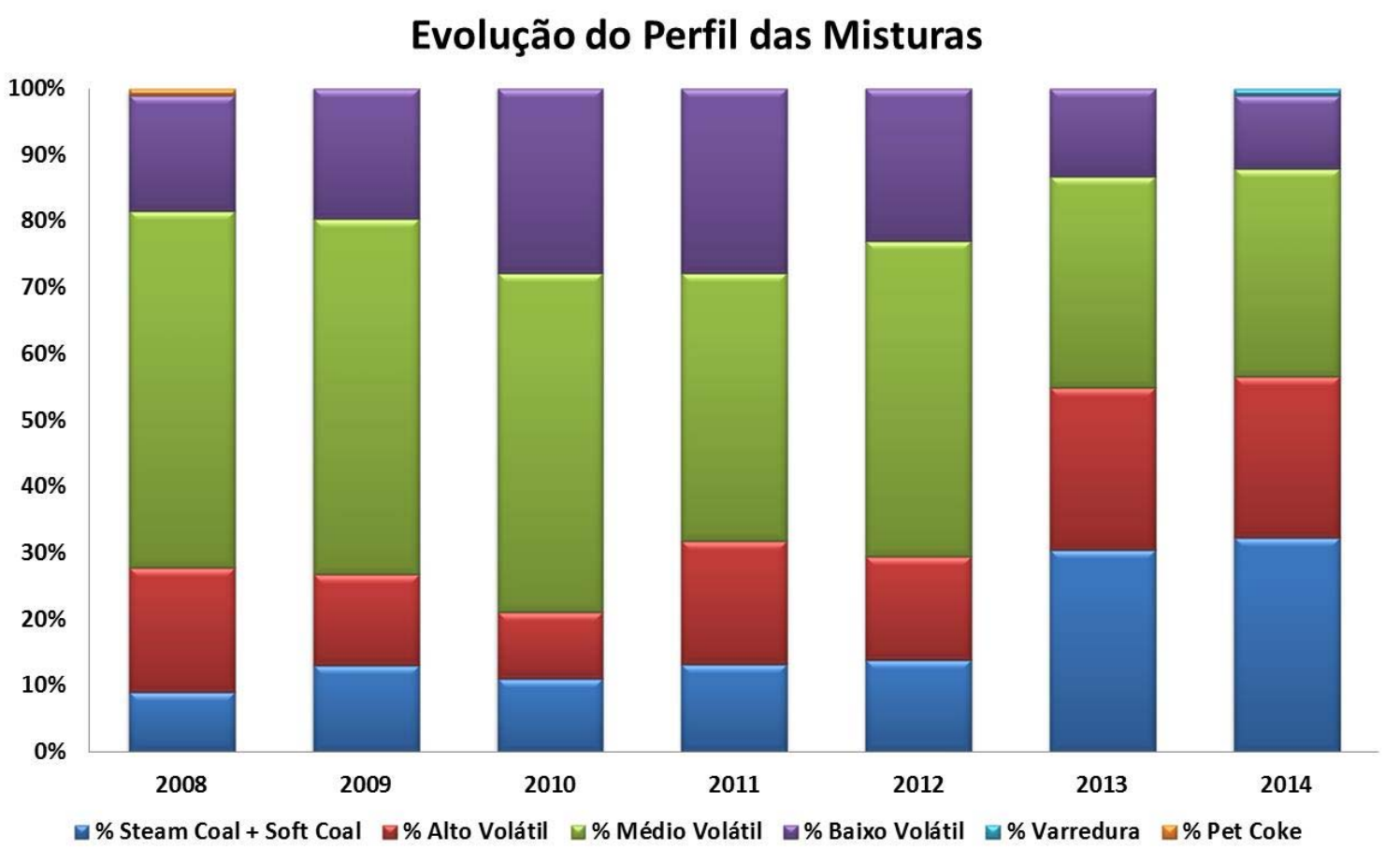

Figura 4. Evolução do Perfil das Misturas (agrupamento por ano)

A modifição do perfil das misturas foi cuidadosamente planejada de modo que não houvesse impactos negativos na qualidade do coque, principalmente CSR (Coke Strenght Reactivity) nem DI 15015 (Drum Index). Por isso, as misturas cuja mudança de perfil fosse bem agressiva, uma série de testes utilizando o método "Box Test" eram realizados de modo a se ter uma maior assertividade quanto à qualidade do coque durante o uso das misturas em escala industrial. Na figura a seguir (figura 5), é mostrada a evolução do CSR do coque bem como o perfil das misturas utilizadas.

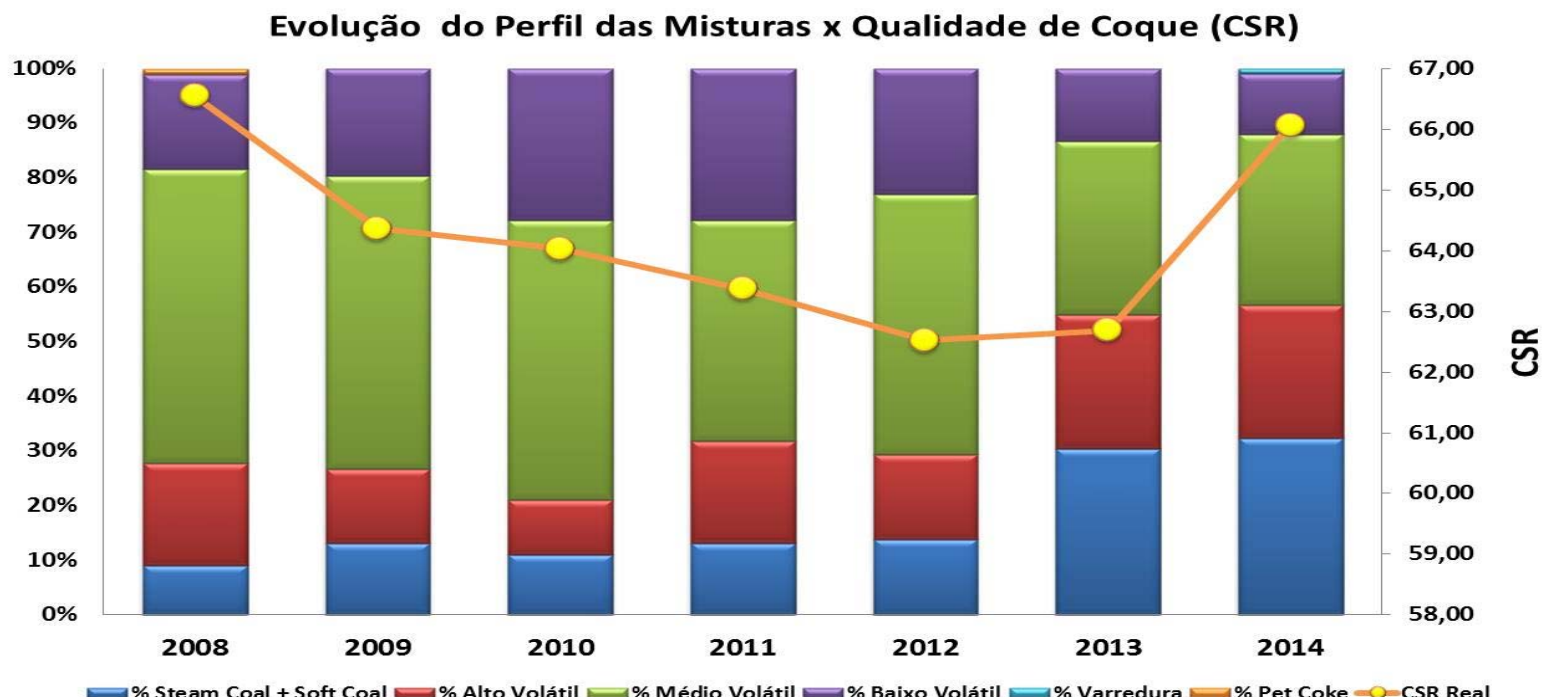

Figura 5. Evolução do Perfil das Misturas (Qualidade do Coque - CSR) 
$\mathrm{Na}$ figura 6, o mesmo gráfico é mostrado, porém com foco no DI. Observa-se que em 2008 o DI era menor do que o especificado. Ações internas foram realizadas de modo a adequação deste parâmetro, principalmente otimização da britagem da mistura. Estas ações, inclusive, foram apresentadas no $41^{\circ}$ Seminário de Redução de Minério de Ferro e Matérias-Primas, de 2011.

Evolução do Perfil das Misturas x Qualidade de Coque (DI)

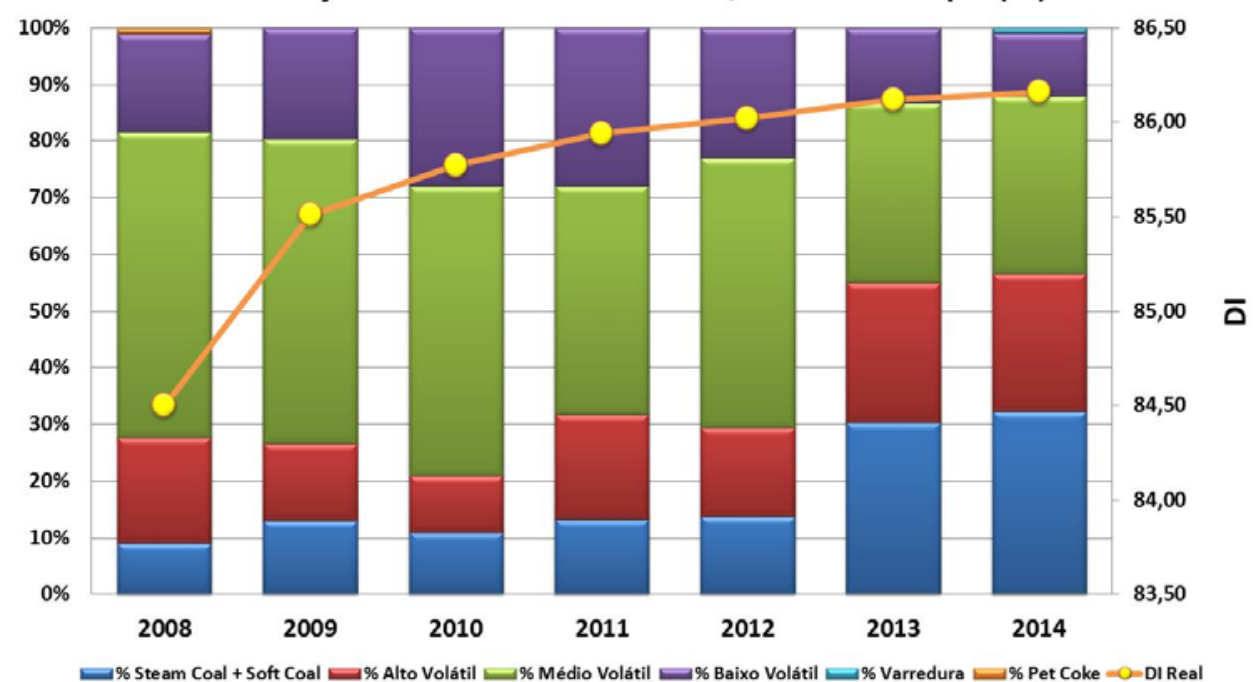

Figura 6. Evolução do Perfil das Misturas (Qualidade do Coque - DI)

Como dito anteriormente, todos os estudos realizados foram centrados em dois grandes pilares: qualidade do coque e custo das misturas. Os dados até aqui mostrados referenciaram-se apenas na qualidade do coque.

Nas figuras que se seguem será mostrada a evolução do custo das misturas correlacionado com as mudanças de perfil e também com a qualidade do coque.

O custo aqui apresentado trata-se de uma relação percentual entre os anos de 2008 e 2014, em que o custo denominado "zero" refere-se ao início do levantamento dos dados. Os valores apresentados nos anos posteriores a 2008 representam a variação do custo em relação ao custo "zero".

A figura a seguir (figura 7), mostra a evolução do custo das misturas (650 misturas) com a qualidade do coque (CSR).

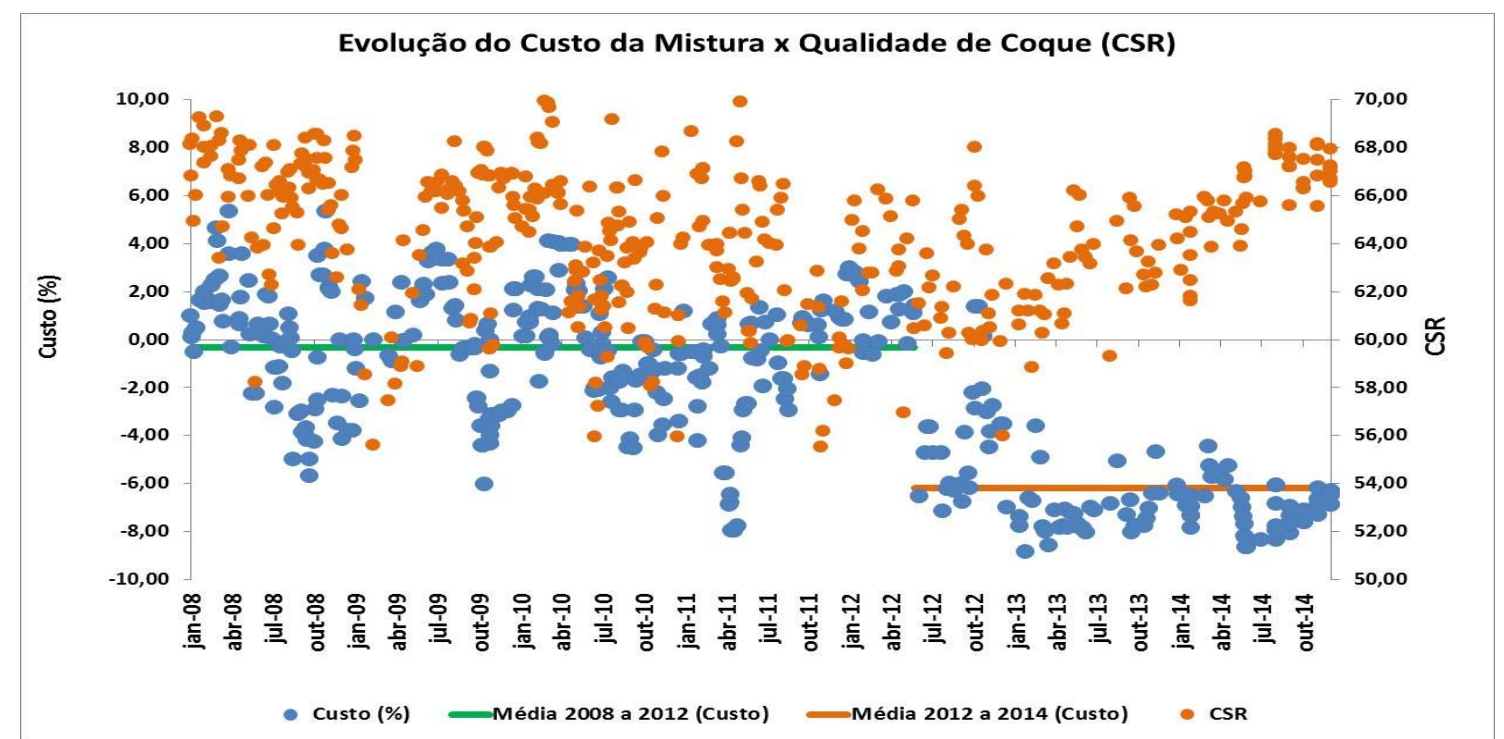

Figura 7. Evolução do Custo das Misturas x Qualidade do Coque - CSR) 
Na figura 8 é mostrada a evolução do custo das mistura e o impacto no DI do coque. Percebe-se que existem dois períodos bem distintos no gráfico: um que vai de 2008 até julho de 2012 e outro a partir de agosto de 2012 até dezembro de 2014.

O grande fator motivador para esta mudança de patamar foi a intensificação dos estudos e ações para a redução do custo das misturas, que se resumem em definição de misturas de diferentes perfis (alta participação de carvões "soft" e "steam coal", redução dos carvões médio voláteis e teste destas misturas através do "Box Test").

Há de se ressaltar que de Novembro de 2011 a maio de 2013, a planta da SunCoke Energy Brasil operou com $50 \%$ de sua capacidade, em função da crise mundial do mercado de aço.

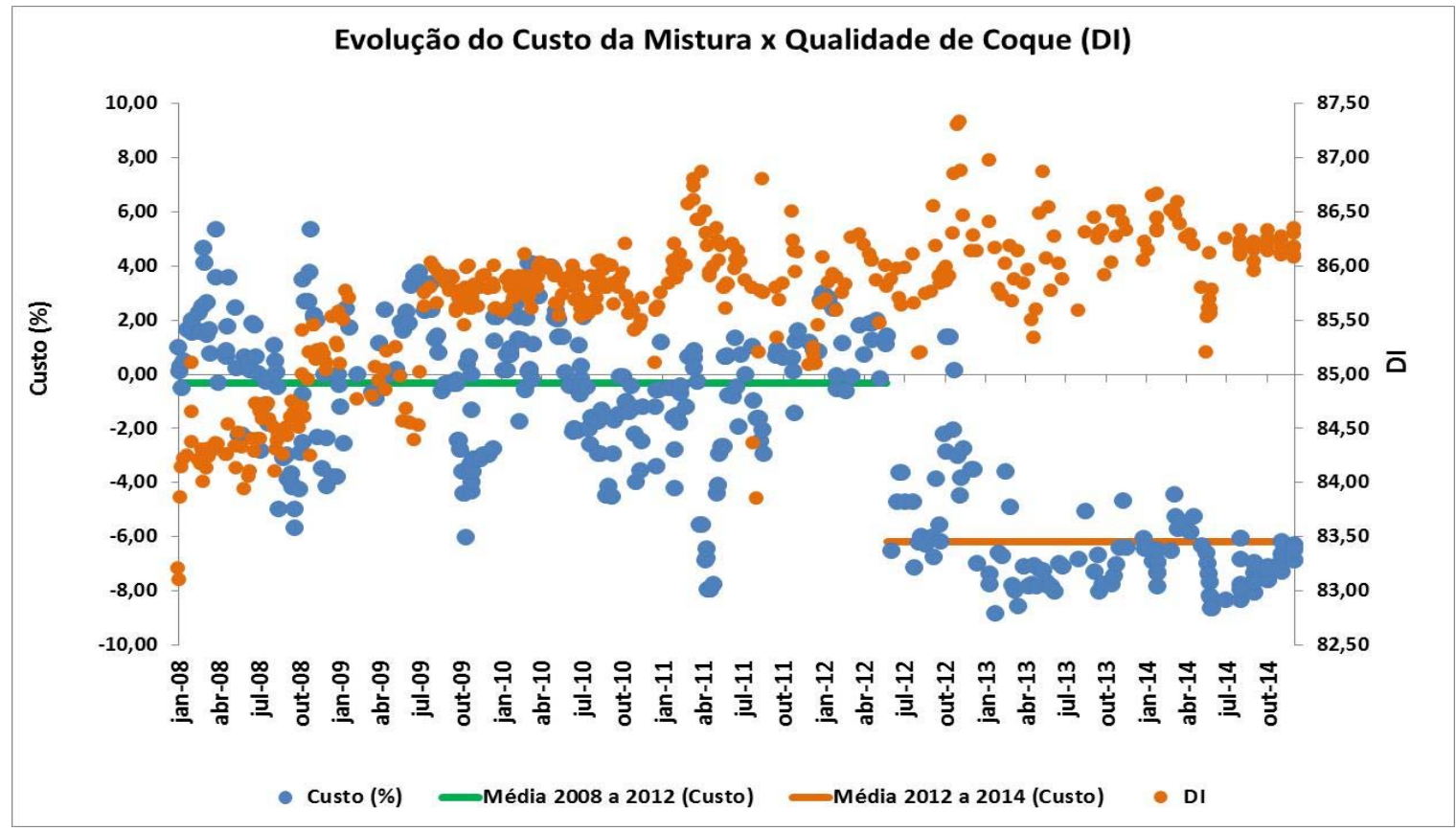

Figura 8. Evolução do Custo das Misturas x Qualidade do Coque - DI)

Na figura 9 é mostrado o custo médio das misturas, agrupadas por ano de utilização evidenciando a qualidade do coque (CSR)

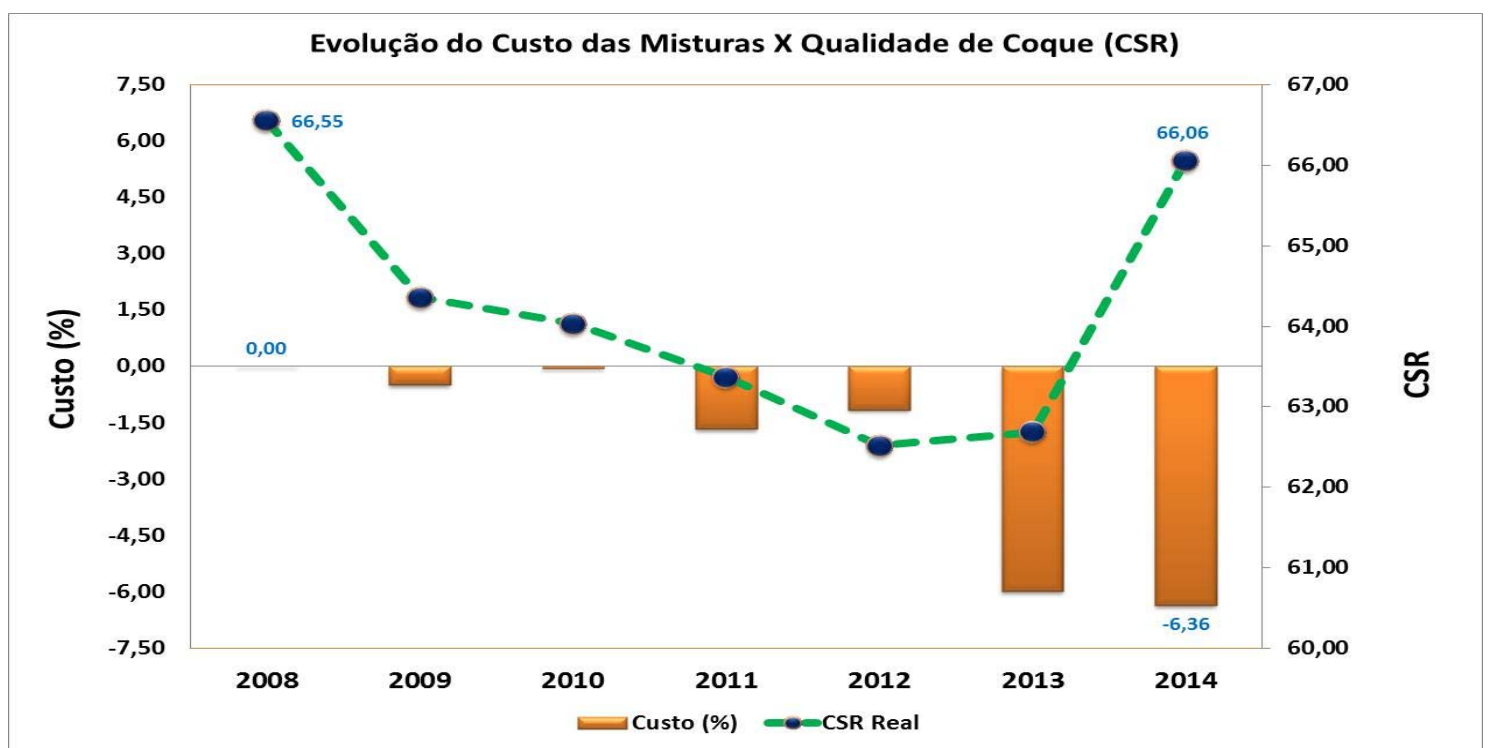

Figura 9. Evolução do Custo Médio das Misturas x Qualidade do Coque - CSR 
Na figura 10 é mostrado o custo médio das misturas, agrupado por ano de utilização evidenciando a qualidade do coque (DI)

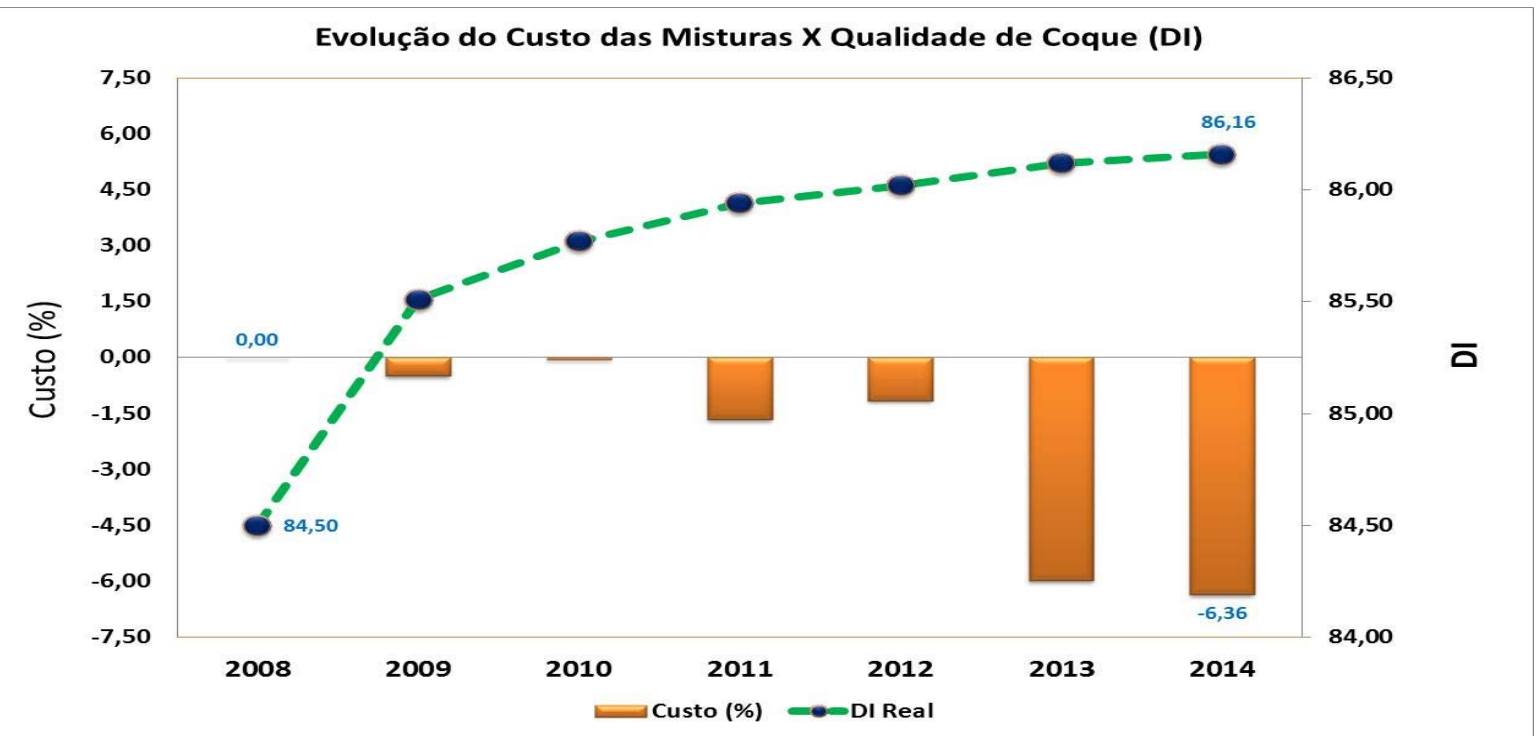

Figura 10. Evolução do Custo Médio das Misturas x Qualidade do Coque - DI

A figura 11 se propõe a mostrar o impacto da mudança do perfil no custo médio das misturas.

Como pode ser observado, houve uma significativa redução do custo médio das misturas em função da elevação criteriosa dos carvões "soft" e "steam coal" combinados com a redução também criteriosa dos carvões médios voláteis.

Evolução do Perfil das Misturas x Custo das Misturas

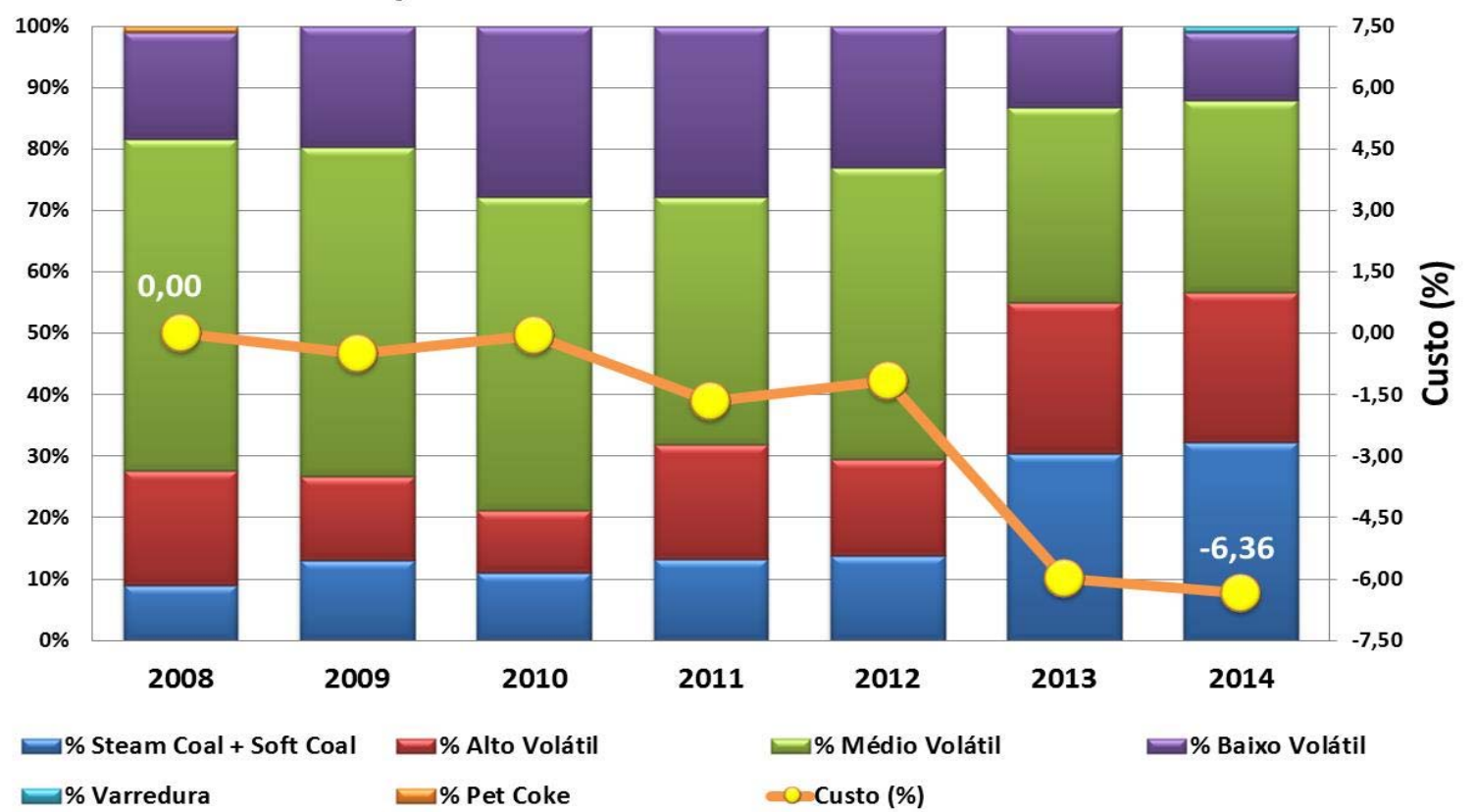

Figura 11. Evolução do Perfil das Misturas x Custo Médio das Misturas 


\section{CONCLUSÃO}

Os dados mostrados comprovam a grande flexibilidade e eficiência da tecnologia heat recovery da SunCoke Energy ao permitir, de forma consistente, o uso de carvões "soft" e "steam coal" em elevados percentuais nas misturas, com impactos positivos na qualidade do coque e redução significativa do custo médio das misturas. Esta afirmação é facilmente confirmada quando se compara o perfil das misturas utilizadas em 2008 com o perfil das misturas utilizadas em 2014. Em 2008 o perfil da mistura era assim configurado: pet coke 1,03\%; carvões baixo voláteis $17,37 \%$; médio voláteis $53,86 \%$; carvões alto voláteis $18,69 \%$ e carvões 'soft" e "steam coal" somados $9,05 \%$; Dl 84,50 e o CSR 66,55 .

Em 2014, o fechamento anual foi uma mistura com a seguinte composição: carvões baixo voláteis $11,00 \%$; carvões médios voláteis $31,30 \%$; carvões altos voláteis $24,35 \%$ e carvões 'soft" e "steam coal" somados $32,35 \%$; DI 86,01; CSR 66,06 e o custo médio 6,36\% menor que o praticado em 2008.

Os números são expressivos e mostram que o percentual de carvões "soft" e "steam coal" teve uma elevação de 23,3 pontos percentuais, o que se caracteriza um consumo 3,5 vezes maior do que o praticado em 2008. Já o percentual de carvões médio voláteis foi reduzido em 22,56 pontos percentuais, cerca de $42 \%$. 0 custo médio, comparando-se os dois períodos, teve uma redução de exatos $6,36 \%$.

Este trabalho não termina aqui, pois estudos continuam sendo desenvolvidos no intuito de se reduzir ainda mais o custo das misturas, preservando, e até mesmo melhorando, a qualidade do coque.

\section{BIBLIOGRAFIA}

1 Ulhôa, M.B. - Procedimento para avaliação preliminar de carvão pelo rank e propriedades reológicas - 2nd International Meeting on Ironmaking - Vitória, Brasil, setembro de 2004.

2 Cornelis, J.K. et all - Médium-volatile coal: The solution for coke oven blends with reduced low-volatile coal content - $S$ teel Technology, july/august 2003.

3 Caldeira, Jorge G. Teoria da Coqueificação. In: Ulhôa, Murilo B. CarvãoAplicado à Fabricação de Coque de Alto Forno. São Paulo: ABM, 2003. p.104-152.

4 Valia, Hardarshan S.; ELLIS Allen R. Non-Recovery Operating Practices From Around the World. In: The Iron \& Steel Technology Conference and Exposition, 2008,Pittburgh, EUA. AisTech, 2008. p.1-21.5. ELLIS, A.R. et all - Heat recovery coke making at Indiana Harbor Coke Company - An historic event for the steel industry - 1999 Ironmaking Conference Proceedings. 